\title{
Design \&Analysis of Efficient Battery Charging / Discharging for Electrical Vehicle
}

\author{
Sangeetha E.P ${ }^{1}$, R.Chandra Prabha ${ }^{2}$, Dr.R.Ilango ${ }^{3}$ \\ Assistant Professor, Department of Electrical and Electronics Engineering, \\ K.Ramakrishnan College of Engineering, Trichy, India ${ }^{1}$ \\ Assistant Professor, Department of Electrical and Electronics Engineering, \\ SCAD Institute of Technology, Palladam, India ${ }^{2}$ \\ Professor, Department of Electrical and Electronics Engineering, \\ K.Ramakrishnan College of Engineering, Trichy, India ${ }^{3}$
}

\begin{abstract}
Electric Vehicle (EV) batteries are participated in the regulation of power flow in grid through battery charger. In this paper Bidirectional battery charger of $12-\mathrm{V}, 4 \mathrm{~A}, 32 \mathrm{~W}$ is proposed. The Bidirectional battery charger circuit comprises of two-stage conversion i.e. DC-AC and AC-DC conversion. Neutral Point Clamped (NPC) converter is used for Bidirectional AC-DC conversion. The battery charger can convert three phase convenient power to charge the batteries of vehicles by providing $12-\mathrm{V}, 4 \mathrm{~A}$. Likewise, the battery charger can discharge back from the connected battery to the load when there is power demand of load in the grid.
\end{abstract}

Keywords: Electric Vehicle, Bidirectional battery charger, Neutral Point Clamped

\section{INTRODUCTION}

Venomous discharge causes ozone consumption, by copying of petroleum products in vehicle application. In ozone layer a bright radiation engrossing limit influence life in earth in various ways. To stay away from this issue EV gain consideration in created countries. Because of developing consideration of utilizing EV, vitality used for electric power in vehicle application. In Non-detached battery chargers is additionally known's single stage converter which is utilized for low power applications $(<250 \mathrm{~W})$ as a rule they are constrained by single controller for Power Factor Correction (PFC). Detached battery chargers comprises of two phase converter, as indicated by power rating it might be single stage or three stages. A high repeat transformer is used for required AC-AC change and imprisonment reason. For high power applications the three-arrange chargers have been picked over single stage.

\section{PROPOSED SYSTEM}

The proposed battery charger has limit of charging the related battery from three-phase AC source and discharging the related batteries to stack when there is a pile ask for on micro grid in islanded mode.

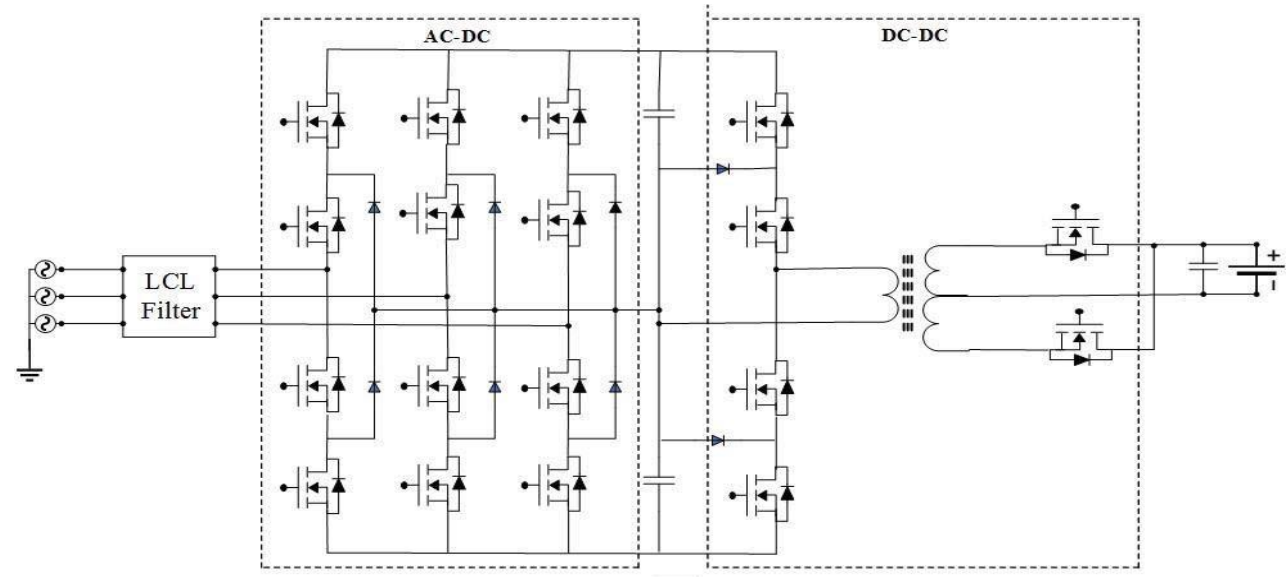

Fig:1 Proposed Battery Charger/Discharging Circuit 


\section{International Journal of Innovative Research in Electrical, Electronics, Instrumentation and Control Engineering}

Vol. 7, Issue 6, June 2019

NPC converter close by DC-interface capacitor sought after by a High-repeat leg related with the commitment of Highrepeat centered taped transformer. The yield of High-repeat centred taped transformer is trailed impressively interface converter. A capacitor channel is related parallel between half-interface converter and the related battery.

\section{CHARGING MODE}

In charging mode, there are two phases in proposed topology for example Air conditioning DC change and DC- DC transformation

A. AC to DC Conversion: For AC-DC change, the NPC converter go about as diode-connect rectifier, the threestages AC voltage convert into DC voltage at DC-interface capacitor through the body-diode of switches of NPC is appeared in Fig 1. The MOSFET switch S3 and S4 turns on, the voltage of DC-interface Capacitor Bus applies over the windings of Centred-taped transformer, the yield twisting of Centred taped transformer progresses toward becoming invigorated and voltage applies over the body diode the MOSFET T2 to accomplish the required yield DC voltage for the associated battery by going through capacitor channel. On the off chance that there is a contrast between put away vitality of $\mathrm{C} 1$ and $\mathrm{C} 2$ in excess of a diode drop, the invigorated capacitor will release through diode to S3 with higher voltage. While the square chart of PI control for DC-DC converter in charging mode

B. DC to DC Conversion: For DC-DC transformation, the DC-interface capacitor gives steady information DC voltages to High-recurrence leg go about as an inverter to change over DC voltages into AC voltages, trailed by Highrecurrence focused tap transformer. The High recurrence focused tap transformer buck the AC voltages in charging mode. Additionally, it gives disengagement amid source blame condition to shield battery from source side blame current. The buck voltage at that point applies crosswise over half-connect converter, go about as a rectifier convert AC voltages into required DC voltage to charge the associated battery. The MOSFET switch S1 and S2 turns on, the voltage of DC-interface Capacitor Bus applies over the windings of Centred-taped transformer, the yield twisting of Centred taped transformer moves toward becoming stimulated and voltage applies over the body diode the MOSFET $\mathrm{T} 1$ to accomplish the required yield DC voltage for the associated battery by going through capacitor channel. In the event that there is a distinction between put away vitality of $\mathrm{C} 1$ and $\mathrm{C} 2$ in excess of a diode drop, the empowered capacitor will release through diode to $\mathrm{S} 2$ with higher voltage.

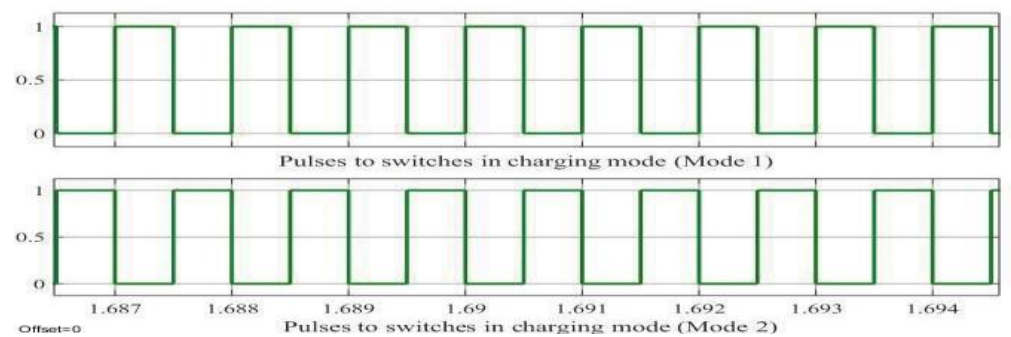

Fig 2. Heartbeats given High-recurrence leg switches in charging mode By PI controller

\section{DISCHARGING MODE}

A. DC to DC Conversion:

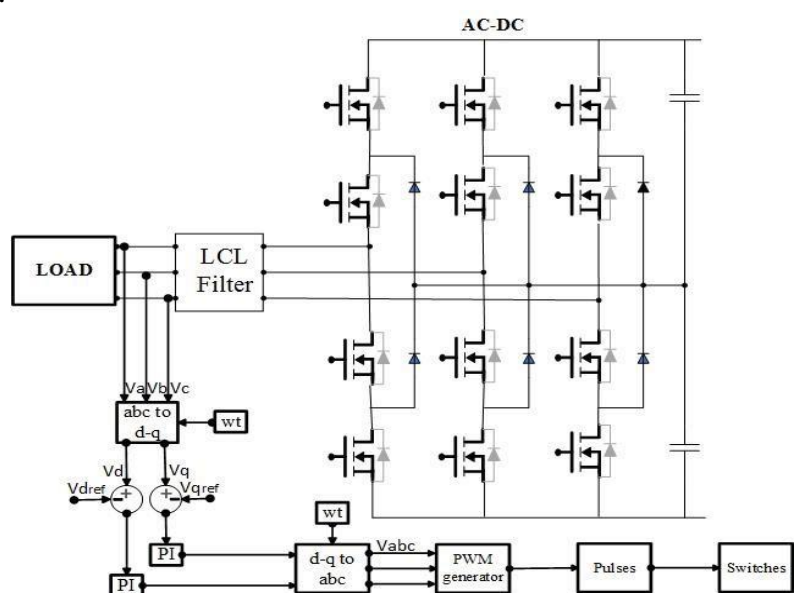

Fig.3 DC-DC converter in releasing mode 


\section{International Journal of Innovative Research in Electrical, Electronics, Instrumentation and Control Engineering}

Vol. 7, Issue 6, June 2019

In Fig 3 , the battery releases the DC voltage goes over the capacitor channel and apply over the MOSFET T1 of half extension converter, convert the DC voltage into AC voltage pursued High-recurrence focused tap transformer, which support the AC voltage. The MOSFET switches S1 and S2 transforms on and convert the AC voltage into DC voltage at DC-connect capacitor transport. On the off chance that there is a contrast between put away vitality of $\mathrm{C} 1$ and $\mathrm{C} 2$ in excess of a diode drop, the stimulated capacitor will release through diode to S1 with higher voltage is appeared in figure. The switches $\mathrm{S} 1, \mathrm{~S} 2$ and $\mathrm{T} 1$ turn $\mathrm{ON}$ and Turns OFF at the same time, so that there is no vitality misfortune in exchanging of these MOSFET switches.

\section{B. DC to AC Conversion:}

For DC-AC transformation, the consistent information DC voltage at DC-interface capacitor apply crosswise over NPC inverter to get three-stages AC yield for burden in islanded mode. A shut circle PI controller is utilized to control the yield three-stages for burden in islanded mode.. By contrasting the $\mathrm{Vd}$ and $\mathrm{Vq}$ and Vdref and Vqref individually goes crosswise over PI controller and change the recently created $\mathrm{Vd}$ and $\mathrm{Vq}$ to three-stages voltage for example $\mathrm{Va}, \mathrm{Vb}$ and Vc within the sight of change point.

\section{DESIGN AND CONTROL}

The proposed circuit is plan for $1 \mathrm{Kw}$ and $48 \mathrm{~V}$ battery. The proposed control parameter and circuit parameters

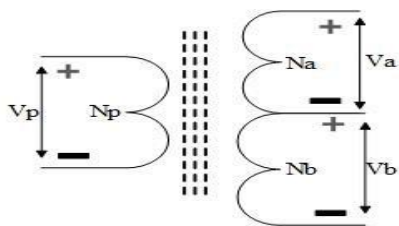

Fig 4. High-Frequency Centered Tap Transformer

The high-recurrence Centered Tap transformer is appeared Fig 4, while the conditions for auxiliary winding $\mathrm{Va}$ and $\mathrm{Vb}$ of High-recurrence Centered tap transformer

\section{RESULT AND DISCUSSION}

A. Charging Mode:

In charging mode, the PI controller is utilized to keep up the yield 48-voltage DC by giving legitimate changing to switches of High-recurrence leg. The yield DC voltage is kept up at $48 \mathrm{~V}$ of proposed battery charger is appeared in Fig 5 while the yield DC current is kept up at 20.83A for the associated battery in charging mode is appeared in Fig 6 .

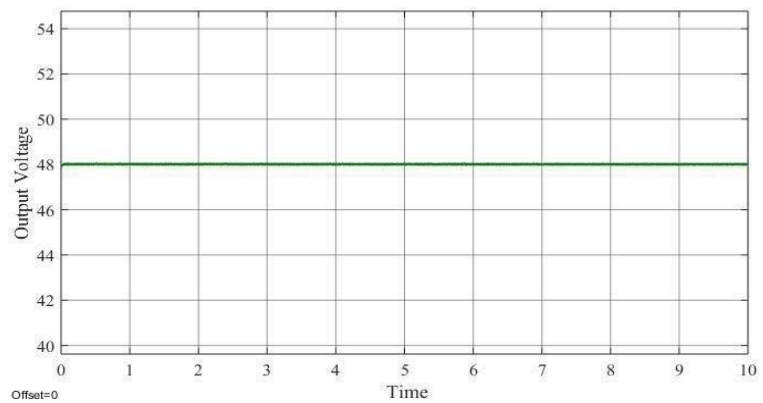

Fig 5. DC output $12 \mathrm{~V}$ for associated battery in charging mode

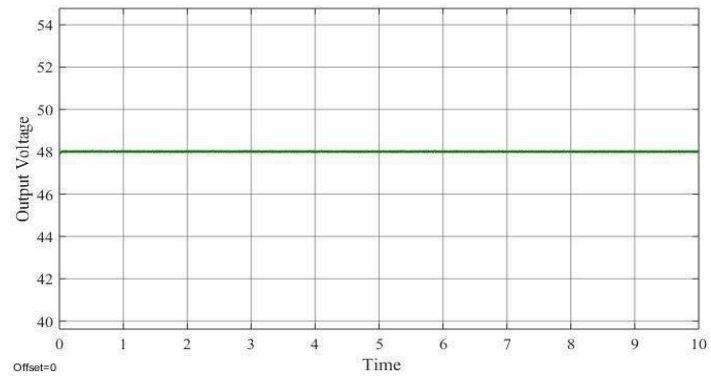

Fig 6. Yield DC current in charging mode to associated batteries 
International Journal of Innovative Research in Electrical, Electronics, Instrumentation and Control Engineering

Vol. 7, Issue 6, June 2019

B. Discharging Mode:

At the point when the proposed battery charger acts in releasing mode, the releasing yield three-stages AC wellspring of the proposed battery charger to stack is Fig 7. And Yield three-stages AC voltages of proposed battery charger to stack is Fig 8.

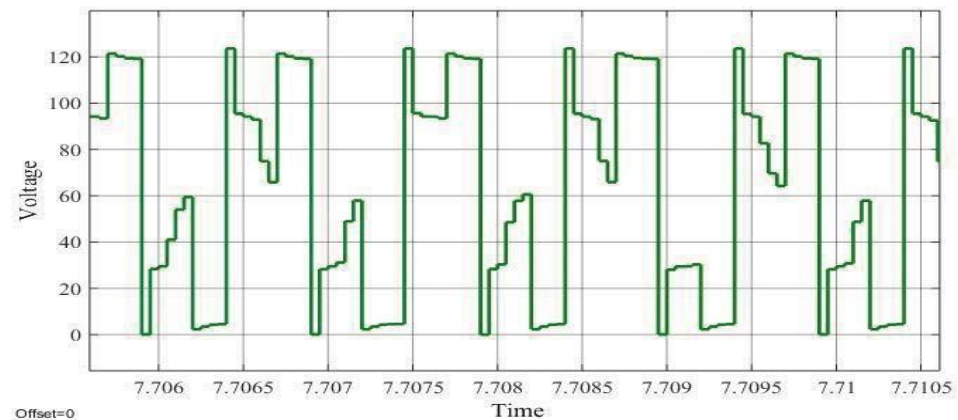

Fig 7. Current wave structure to MOSFET in charging mode

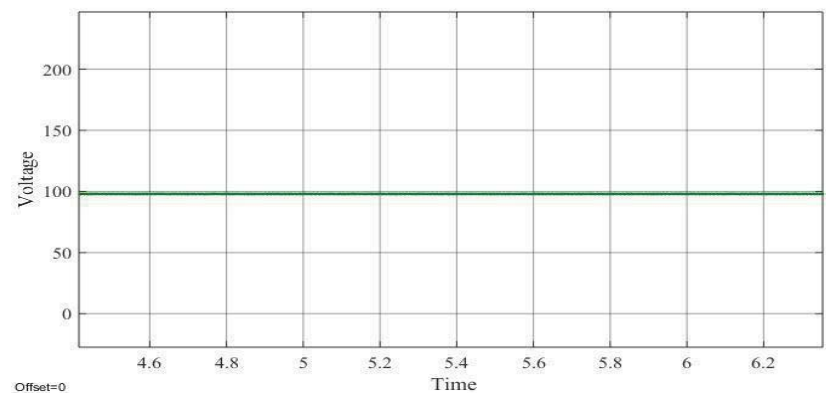

Fig 8. Yield three-stages AC voltages of proposed battery charger to stack

While the present stream to NPC MOSFET and voltage crosswise over MOSFET because of shut circle of PI controller is appeared in Fig 9 and Fig 10 individually

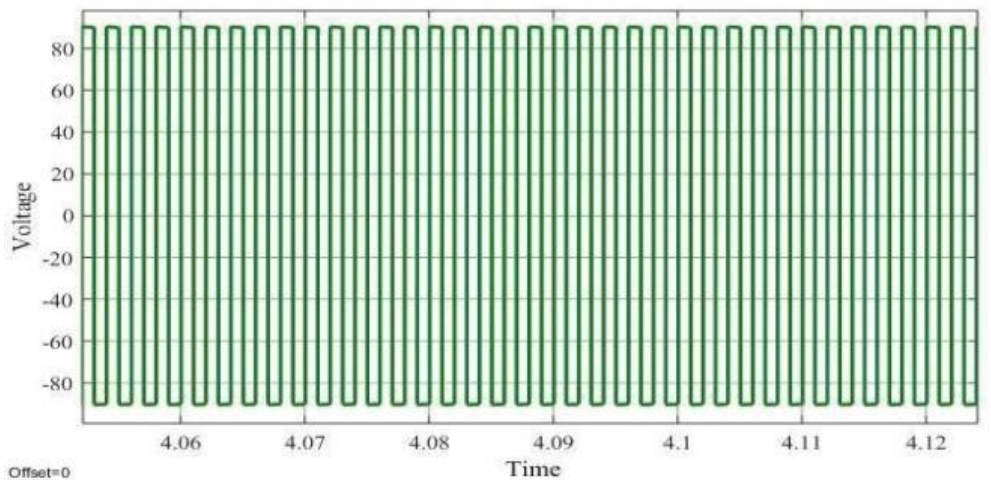

Fig 9. High-recurrence focused tap transformer yield in releasing mode

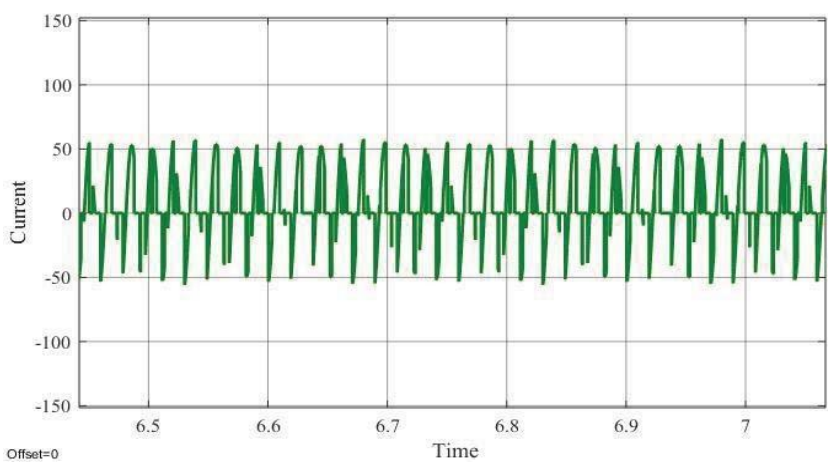

Fig 10. Current streaming to MOSFET of NPC through shut circle PI controller 


\section{IJIREEICE \\ International Journal of Innovative Research in Electrical, Electronics, Instrumentation and Control Engineering}

Vol. 7, Issue 6, June 2019

The proposed battery topology is referenced. For AC to DC activity, a widespread scaffold is utilized involves 12 switches having Low voltage and current burdens while for DC to DC task, a bidirectional converter is utilized contained 6 switches having Low voltage and current worries crosswise over MOSFET switches.

\section{CONCLUSION AND FUTURE WORK}

A $12-\mathrm{V}, 32 \mathrm{~W}$ disconnected bidirectional battery charger is proposed in this paper. The proposed battery charger circuit worked in islanded mode, involves two-arrange change for example Air conditioning DC and DC-DC transformation..A battery charger can release back the associated battery to stack when there is control request of burden in islanded method of microgrid.

\section{REFFERENCES}

[1]. B. Xu, H. Wang, H. Sun, and Y. Wang, "Design of a bidirectional power converter for charging pile based on V2G," in Industrial Technology (ICIT), 2017 IEEE International Conference on, 2017, pp. 527-531.

[2]. J. Li, D. Wang, W. Wang, and J. Jiang, "Minimize Current Stress of Dual-Active-Bridge DC-DC ConvertersforElectricVehiclesBasedonLagrange MultipliersMethod,"EnergyProcedia,vol.105,pp. 2733-2738,2017.

[3]. M. Jayalakshmi, G Asha and K Keerthana , "Control of Single Phase Z-Source Inverter Fed Induction Motor Using Simple Boost Controller", International Journal of Emerging Trends in Electrical and Electronics, vol.10,issue 10,pp.44-48,2014

[4]. M. P. Pritam Das, and Gerry Moschopoulos, "Analysis and design of a new ac-dc single stage Full-bridge PWM Converter with two Controllers," IEEE Transactions on Industrial Electronics, vol. 60, November 20132013

[5]. Mukesh . R Dhayalini.K, "Optimal setting and sizing of distributed solar photovoltaic generation in an electrical distribution IEEE international conference on innovations in power and advanced computing technologies (i-PACT 2019)

[6]. Dhayalini. K , Optimal allocation of distributed solar photovoltaic generation on electrical distribution system under uncertainties", , 2018, Journal of Engineering Research, Kuwait University

[7]. H. S. R. a. B. V. Borges, "New Optimized Full- Bridge Single-Stage AC/DC Converters," IEEE Transactions on Industrial Electronics, vol. 58, pp. 2397 - 2409, 23 July 20102011.

[8]. K.Dhayalini N.Vinothini, K Dhayalini, N Vinothini "Design of multilevel inverter using Nearest Level Control Technique with reduced power switches," - 2018 4th International Conference on Electrical Energy ..., 2018

[9]. Y. C. H. H. L. Cheng, and C. S. Lin, , "A novel single-stage high-power factor AC/DC converter featuring high circuit efficiency," IEEE Transactions on Industrial Electronics, vol. 58, pp. 524-532, 12 April 20102011

[10]. K. Dhayalini1, R. Mukesh, "Active Power Filter For Vehicle to Grid(V2G) Applications using Bidirectional Conversion Technique in Manufacturing Industries”, International Journal of Pure and applied mathematics,volume:118,Issue:18,

[11]. W. Y. C. J. M. Kwon, and B. H. Kwon, "Single- stage quasi-resonant flyback converter for a cost- effective PDP sustain power module," IEEE Transactions on Industrial Electronics, vol. 58, pp. 2372-2377, 05 August 20102011.

[12]. D Aarthi, R Manivasagam, "Design and Implementation of UPFC Using Ten Switch Converter With Switch ReductionInternational Journal Of Engineering And Computer Science,volume:6,Issue:6

[13]. J. C. a. I. Barbi, "A three-phase high power factor PWM ZVS power supply with a single power stage," presented at the Power Electronics Specialists Conference, PESC '94 Record., 25th Annual IEEE, Taipei, Taiwan,1994.

[14]. A.Durgadevi, K.Dhayalini, "IOT based design and analysis of robotic vehicle movement for military applications International Journal of Innovations \& Advancement in Computer science,2017, volume:6,Issue:11 